\title{
Developing and sustaining specialist and advanced practice roles in nursing and midwifery: A discourse on enablers and barriers
}

\author{
Gerard M. Fealy \\ University College Dublin \\ Mary Casey \\ University College Dublin \\ Denise O'Leary \\ Technological University Dublin, denise.oleary@tudublin.ie
}

See next page for additional authors

Follow this and additional works at: https://arrow.tudublin.ie/tfschhmtart

Part of the Medicine and Health Sciences Commons

\section{Recommended Citation}

Fealy, GM, Casey, M, O'Leary, DF, et al. Developing and sustaining specialist and advanced practice roles in nursing and midwifery: A discourse on enablers and barriers. J Clin Nurs. 2018; 27: 3797- 3809. DOI:

10.1111/jocn. 14550

This Article is brought to you for free and open access by the School of Tourism \& Hospitality Management at ARROW@TU Dublin. It has been accepted for inclusion in Articles by an authorized administrator of ARROW@TU

Dublin. For more information, please contact

arrow.admin@tudublin.ie, aisling.coyne@tudublin.ie, gerard.connolly@tudublin.ie.

Funder: Irish Department of Health

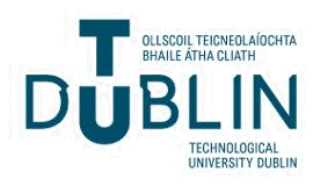




\section{Authors}

Gerard M. Fealy, Mary Casey, Denise O'Leary, Martin S. McNamara, Denise O'Brien, Laserina O'Conner, Rita Smith, and Diarmuid Stokes 


\title{
Developing and sustaining specialist and advanced practice roles in nursing and midwifery: A discourse on enablers and barriers
}

\author{
Gerard M Fealy PhD, MEd, RGN, Professor ${ }^{1}$ (D) | Mary Casey MSc, PhD, RGN, Associate \\ Professor $^{1}$ | Denise F O'Leary BSc, PhD, PGDip, Assistant Head of School ${ }^{2}$ | \\ Martin S McNamara MA, EdD, RGN, Professor ${ }^{1}$ | Denise O'Brien MSc, PhD, RM, Assistant \\ Professor $^{1}$ | Laserina O'Connor PhD, RANP, RNP, Professor ${ }^{1}$ (D) | Rita Smith PhD, MEd, \\ RGN, Assistant Professor ${ }^{1}$ (D) | Diarmuid Stokes BA, MSc, PGDip, Liaison Librarian ${ }^{3}$
}

\author{
${ }^{1}$ UCD School of Nursing, Midwifery and \\ Health Systems, University College Dublin, \\ Dublin, Ireland \\ ${ }^{2}$ School of Hospitality Management and \\ Tourism, Dublin Institute of Technology, \\ Dublin, Ireland \\ ${ }^{3}$ UCD Library, University College Dublin, \\ Dublin, Ireland

\section{Correspondence} \\ Gerard M Fealy, UCD School of Nursing, \\ Midwifery and Health Systems, University \\ College Dublin, Dublin, Ireland. \\ Email: gerard.fealy@ucd.ie \\ Funding information \\ This study is part of a study funded by the \\ Irish Department of Health.
}

Aims and objectives: To collate, synthesise and discuss published evidence and expert professional opinion on enablers and barriers to the development and sustainability of specialist and advanced practice roles in nursing and midwifery.

Background: Expanded practice is a response to population health needs, healthcare costs and practitioners' willingness to expand their scope of practice through enhanced responsibility, accountability and professional autonomy.

Design: This discursive paper is based on a rapid review of literature on enablers and barriers to the development and sustainability of specialist and advanced practice roles and is part of a wider policy analysis.

Methods: We analysed and synthesised of 36 research articles, reviews and discussion papers on enablers and barriers in the development and sustainability of expanded practice roles.

Results: Several factors enable role expansion, including: role clarity; credentialing and endorsement; availability of education for expanded roles; individual practitioners' dispositions towards role expansion; support from peers, other professionals and the work organisation; and costs. Where limited or absent, these same factors can constrain role expansion.

Conclusions: Enabling nurses and midwives to practice to their full scope of education and expertise is a global challenge for disciplinary leadership, a national challenge for professional regulation and a local challenge for employers and individual clinicians. These challenges need to be addressed through multistakeholder coordinated efforts at these four levels.

Relevance to clinical practice: This discursive paper synthesises empirical evidence and expert professional opinion on the factors that enable or hinder the development and sustainability of specialist and advanced practice roles. Providing a critical appraisal of current knowledge, it provides a reference source for disciplinary debate and policy development regarding the nursing and midwifery resource and informs clinicians of the myriad issues that can impact on their capacity to expand their scope of practice. 


\section{KEYWORDS}

advanced practice, development, discourse, midwifery, nursing

\section{AIMS}

The aim of this study was to collate, synthesise and discuss published evidence and expert professional opinion on enablers and barriers to the development and sustainability of specialist and advanced practice roles in nursing and midwifery.

\section{2 | BACKGROUND}

The emergence of specialist and advanced practice roles in nursing and midwifery is an expression of expanded practice and reflects nurses' and midwives' willingness to expand the scope of their practice through enhanced responsibility, accountability and professional autonomy in patient care and to enhance career prospects. These roles also reflect population and health service needs and were initially developed from population health needs, such as those of isolated rural communities in the United States and Canada, which necessitated practice expansion and delegated medical authority, to provide a range of diagnostic and treatment services (Browne \& Tarlier, 2008). Other drivers for developing advanced practice roles include the need to improve access to healthcare services and to address the limited availability of doctors (Fougère et al., 2016). In several countries, discussions on how best to respond to a growing demand for health care are also taking place in the context of government budgetary constraints and discussions on how to control the growth in health spending (Darker, 2013; Delamaire \& Lafortune, 2010; Ham, Dixon, \& Brooke, 2012).

Aside from providing direct care, advanced practitioners deploy their considerable knowledge and experience in coordinating and directing other carers, including family carers (Bradway et al., 2012). Although empirical evidence indicates that expanding practice through specialist and advanced practice roles has both clinical and practitioner benefits (Begley et al., 2010; Drennan et al., 2009), there is also evidence that there are obstacles and challenges to the successful development, practical implementation and sustainability of these roles in nursing and midwifery (Begley et al., 2010; Drennan et al., 2009; Fealy et al., 2015; Heale \& Rieck-Buckley, 2015).

This discursive paper examines and synthesises the factors that either enable or hinder the development and sustainability of specialist and advanced practice roles in nursing and midwifery, including the factors that influence the ability of practitioners to operate effectively in the roles and to practice to optimal scope of practice. The study is part of a wider policy analysis, which the authors prepared on behalf of the Irish Department of Health, and which subsequently informed the development of a position paper proposing "an evidence-based, patient-centred policy framework" for the

\section{What does this paper contribute to the wider global clinical community?}

- Practice expansion remains an enduring and significant challenge for nursing and midwifery across clinical practice, education and professional regulation, as well as wider health and organisational policy and practice.

- Expanded practice roles are regulated, interpreted and expressed differently across many countries, and the extent to which specialist and advanced practice roles can develop and become enacted is contingent on several factors, acting as either enablers or barriers.

- This discursive paper offers a synthesis of empirical evidence and expert professional opinion on the factors that enable or hinder the development and sustainability of specialist and advanced practice roles, providing a succinct critical appraisal of the state of knowledge, for clinicians and policymakers.

development of a graduate, specialist and advanced nursing and midwifery workforce (Department of Health, 2017). The aim of the policy was to develop a critical mass of graduate, specialist and advanced practice nurses and midwives in Ireland, an initiative that is viewed as critical to addressing emerging and future health service needs. The position paper, in turn, resulted in a new training programme for advanced practice nurses, which commenced on a national basis in October 2017. By collating and synthesising empirical evidence and expert opinion on an aspect of professional advancement, this discursive paper adds to what is already known about a topic that continues to exercise the profession. The rapid review addressed the following question: What are the enablers and barriers to the development of specialist and advanced nursing and midwifery practice roles from a legislative regulatory, policy, education and service delivery perspective?

\section{DESIGN}

This discursive paper is based on a rapid review of the literature on the development of expanded practice roles, specifically specialist and advanced practice roles. We limited the initial search to the English language and to two databases, the Cumulative Index to the Nursing and Allied Health Literature (CINAHL) and PubMed (MEDLINE) (O'Leary et al., 2017), and the initial search period for the rapid review was 2012 to 31 October 2015; however, for the present 
TABLE 1 Inclusion and exclusion criteria

\begin{tabular}{|c|c|}
\hline Included & Rationale \\
\hline $\begin{array}{l}\text { Empirical studies and synthesised } \\
\text { evidence from review articles } \\
\text { on the topic }\end{array}$ & $\begin{array}{l}\text { Peer-reviewed empirical studies and review articles provide high levels of evidential support in the } \\
\text { evidence hierarchy }\end{array}$ \\
\hline $\begin{array}{l}\text { Discursive papers on the topic, } \\
\text { including discussion of professional } \\
\text { policy and regulation and credentialing }\end{array}$ & $\begin{array}{l}\text { The inclusion of other discursive papers on the topic was consistent with our research } \\
\text { question: "What are the enablers and barriers to the development of specialist and advanced } \\
\text { nursing and midwifery practice roles?" }\end{array}$ \\
\hline $\begin{array}{l}\text { Policy documents and regulatory } \\
\text { frameworks }\end{array}$ & $\begin{array}{l}\text { Although policy documents and regulatory frameworks, as sources, provide a lower level of } \\
\text { evidential support in the evidence hierarchy, the nature of the research question necessitated their } \\
\text { inclusion (O'Leary et al., 2017) }\end{array}$ \\
\hline Excluded & Rationale \\
\hline $\begin{array}{l}\text { Empirical studies reporting } \\
\text { service user perspectives }\end{array}$ & $\begin{array}{l}\text { The search criteria for rapid reviews are usually not as broad as recommended for a Cochrane systematic review } \\
\text { (Higgins \& Green, 2011) }\end{array}$ \\
\hline Editorials and commentaries & $\begin{array}{l}\text { Restricting data sources or the types of papers provides a means of simplifying the steps in a systematic review } \\
\text { (O'Leary et al., 2017) }\end{array}$ \\
\hline
\end{tabular}

discussion, we extended the review dates back to 2004 and forward to 31 December 2016 to ensure that important publications on the topic were included. We used Standard Boolean operators AND, OR and NOT to combine search terms for the following key words and phrases, either individually and in combination: "nursing," "midwifery," "advanced practice," "specialist practice," "practitioner," "scope of practice," "role expansion," "enablers," "barriers."

The sources included empirical studies, synthesised evidence from review articles on enablers and barriers, and discursive papers on the development and sustainability of specialist and advanced practice roles, including discussion of professional policy and regulation and credentialing of expanded scope of practice. Based on the agreed inclusion criteria, two authors (GF, DO'L) independently screened all items retrieved and then reached consensus on the final inclusion. We included articles that reported empirical studies and synthesised evidence from review articles on the topic of specialist and advance practitioner roles. We also included published articles that discussed the development and sustainability of specialist and advanced practice roles. This included discursive papers on health and professional policy dimensions of the roles, including legislative, regulatory, credentialing and licensing, and service delivery perspectives. We excluded empirical studies reporting service user perspectives, as well as editorials and commentaries. Table 1 summarises and explains the inclusion and exclusion criteria for the rapid review. The initial rapid review of literature yielded a total of 196 articles relevant to the topic of enablers and barriers (O'Leary et al., 2017), and the expanded search and item screening resulted in a total of 38 items for inclusion, as follows: 22 empirical studies, 8 reviews and 8 discursive and policy discussion papers $(n=8)$.

\section{4 | RESULTS}

This discursive paper is presented as a narrative synthesis under the following six thematic headings: conceptual confusion and role clarity; endorsement and credentialing; education and training; individual practitioners and their scope of practice; the work organisation; and cost. Table 2 summarises the types of paper included in the rapid review and indicates how each contributed to the six thematic headings. Items are listed in the order that they appear in the paper.

\subsection{Conceptual confusion and role clarity}

Critical to the development and sustainability of specialist and advanced practice roles is definitional clarity. The lack of a clear definition of phrases like "advanced practice nursing" and "advanced nursing practice" has resulted in considerable confusion, which, in turn, arises from how the terms are conceptually distinct from one another and from the variability in how the terms are interpreted in different countries and contexts (Gardner, Chang, \& Duffield, 2007; Lowe, Plummer, O'Brien, \& Boyd, 2012). Associated phrases that seek to explain, such as "extended practice," "expanded practice" and "scope of practice," are similarly contentious. The difference between phrases like "advanced practice nursing" and "advanced nursing practice" lies in whether one is referring to what nurses do, that is, "advanced nursing practice," or to the level at which the roles are constructed, that is, "advanced practice nursing" (Bryant-Lukosius, DiCenso, Browne, \& Pinelli, 2004). In Australia, for example, expanded practice is not synonymous with either advanced nursing practice or advanced practice nursing, but may refer to specific situations in which experienced nurses are authorised to practice beyond the RN scope of practice in a specific context (Stasa, Cashin, Buckley, \& Donoghue, 2014). In that country, definitional clarity was an essential prerequisite before nurse practitioner (NP) practice standards could operate effectively (Cashin et al., 2015).

Conceptualised as involving key activities related to research, education, practice, system support and leadership (Cashin et al., 2015), the clinical nurse consultant (CNC) role is analogous to the advanced practice role and the practice nursing role. However, the $\mathrm{CNC}$ role has been dogged by conceptual confusion due to lack of clarity over role function (Giles, Parker, \& Mitchell, 2014). In the case of midwifery, there is also widespread international variance in 
TABLE 2 Summary of selected items and their contribution to the rapid review

\begin{tabular}{|c|c|c|}
\hline Theme $^{a}$ & Authors & Paper type and method \\
\hline \multicolumn{3}{|c|}{ Empirical studies based on primary data $(n=22)$} \\
\hline 1 & Cashin et al. (2015) & $\begin{array}{l}\text { Empirical study involving stakeholder } \\
\text { consultation, using mixed-methods design }\end{array}$ \\
\hline 1 & Gardner et al. (2007) & $\begin{array}{l}\text { A report on an interpretive, qualitative study } \\
\text { of the practice of nine advanced practice } \\
\text { nurses working in three acute care hospitals } \\
\text { Queensland, Australia, in } 2006\end{array}$ \\
\hline
\end{tabular}

1

Giles et al. (2014)

1, $5 \quad \begin{aligned} & \text { Campbell and } \\ & \text { Profetto-McGrath } \\ & \text { (2013) }\end{aligned}$

1, 3, 4, $5 \quad$ Franks and Howarth (2012)

1, 4, $5 \quad$ Gerrish et al. (2012)

1, 2, 4, 5, 6 Poghosyan

et al. (2013)

1, 2, 3, 4, $5 \quad$ Fealy et al. (2015)

$1,2,3,4 \quad \begin{aligned} & \text { Heale and } \\ & \text { Rieck-Buckley (2015) }\end{aligned}$

1, $6 \quad$ Sharpe (2014)

2, $4 \quad$ Higgins et al. (2014)
A study protocol of a sequential mixed method design, underpinned by Realistic Evaluation, to explore how Nurse Consultants contribute to organisational outcomes

A mixed-methods design to describe the challenges that clinical nurse specialists (CNS) face in their role and how CNSs describe the skills and attributes needed to promote EBP in their workplaces

A study reporting the findings of a SWOT analysis to establish the key attributes of nurse consultants employed in safeguarding children

A multiple case study of 23 APNs to identify factors that influence APNs' ability to promote EBP among front-line nurses

A qualitative descriptive study to investigate nurse practitioner (NP) roles and responsibilities as primary care providers and their perceptions about barriers and facilitators to their scope of practice (SOP)

A survey design to describe practitioners' selfreported facilitators and barriers to expanding scope of practice

A survey to examine the status of advanced practice nursing regulation globally structured interviews among 24 rural NPs in the United States

Contribution to the theme headings

Article describes the context and development of the new Nurse Practitioner Standards for Practice in Australia

The authors conclude that the study findings differentiate advanced practice nurse and nurse practitioner roles, and offer an operational framework to identify, establish and evaluate advanced and extended nursing positions

The study protocol includes extensive stakeholder perspectives to understand the relational and integrated nature and impact of the ANP role

The findings indicate that CNSs experience role strain, lack of support and resources, and role ambiguity

The analysis indicated that the Nurse consultant role was neither wholly strategic nor clinical and that role ambiguity resulted in the role being potentially expendable

Aspects of the APN role included their sphere of responsibility and workload and APN role specifications should provide the opportunity to promote EBP

The findings indicated that the regulatory environment, lack of comprehension of the NP role, and challenging work environments limit successful NP practice

The study reported on the self-reported perceived barriers to practice expansion, which included fear of legal consequences, time restrictions and lack of remuneration

The study reported a wide variation in educational requirements, regulation and scope of practice of advanced practice nurses and identified the barriers to advanced practice nursing as being linked to the status of legislation and credentialing in specific jurisdictions

The study reported that NP social entrepreneurs experience difficulties related to scope of practice, business skills and role conflict

The study reported that there were four mediating factors influence the specialist/ advanced practitioner's ability to perform a leadership role: the presence of a framework for the professional development of the role; opportunities to act as leaders; mechanisms for sustaining leadership; and personal attributes of practitioners

(Continues) 
TABLE 2 (Continued)

\begin{tabular}{cll} 
Theme $^{\mathrm{a}}$ & Authors & Paper type and method \\
\hline 3 & Fagerström (2009) & $\begin{array}{l}\text { A survey method consisting of twenty-four } \\
\text { nurse managers and focus group interviews } \\
\text { with forty-six clinical nurse specialists }\end{array}$ \\
\end{tabular}

3,4

Drennan et al. (2009)

3

\section{3,5}

McKenna et al. (2015)

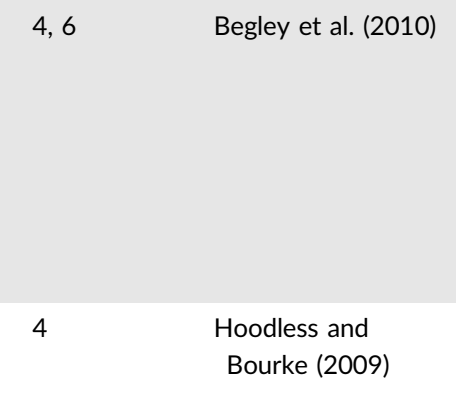

Wilkes et al. (2015)

\section{4}

Casey et al. (2015) the financial implications of clinical specialist and advanced practitioner posts for the Irish health services, in terms of efficiency and effectiveness

A survey that compared job satisfaction between enrolled nurses (ENs) with recent medication endorsement and a group who elected not to undertake the course in a small, isolated health service. The study also nurses to examine their expanded scope of practice

A survey among clinical nurse consultants in
A report of a multiphase, mixed-methods evaluation study to examine the effectiveness in practice of introducing independent nurse and midwife prescribing in Ireland
A survey of 209 learners who had participated in continuing education (CE) programme offered to determine the continuing education needs of primary healthcare nurse practitioners in Ontario, Canada

A study involving semi-structured interviews with twenty-three leaders from nursing, general practice and professional organisations to develop a framework to support the development of advanced nursing roles in general practice in Australia

\section{Contribution to the theme headings}

The study reported that the expanded nursing role included advanced clinical skills and responsibility for health prevention and promotion, education, supervision, leadership, research and development. This implies that legislation, scope and models must be supported and further developed to promote the full scope of advanced practice

The study included evidence of the factors facilitating and inhibiting the development of nurses and midwives' prescribing practice. The principal barriers to the development of prescribing practice included issues surrounding the prescribing of unlicensed medications and limitations placed on prescribing controlled drugs

The study reported on nurse practitioners' self-reported CE needs, including barriers to engaging in and accessing continuing education offerings

The study reported on the barriers and facilitators to the development of advanced nursing roles in general practice. Enabling and inhibiting factors were related to increasing awareness and attractiveness of practice nursing, health reform activities, practice limitations, education and professional development

The study reported that the scope of professional practice is influenced by both practitioner-level and organisational-level factors, which can act as enablers or barriers to practitioners' capacity to operate to their optimal scope or to expand their practice

The study included evidence on nurses' and midwives' experiences of specialist and advance practice roles and included an economic analysis of the CNS and ANP roles involved interviews with medication-endorsed Australia to examine their self-reported role domains and functions
The study reported on the five domains of practice in which clinical nurse consultants work; the study identified that clinical service and consultancy were the predominant domains, although the least emphasis was on the domain of research 
TABLE 2 (Continued)

\begin{tabular}{|c|c|c|}
\hline Theme $^{a}$ & Authors & Paper type and method \\
\hline 4 & Donelan et al. (2013) & $\begin{array}{l}\text { A US national postal survey of physicians and } \\
\text { nurse practitioners in primary care practice to } \\
\text { examine their perspectives on primary care } \\
\text { practice, including scope of work, practice } \\
\text { characteristics and attitudes about the effect } \\
\text { of expanding the role of nurse practitioners } \\
\text { in primary care }\end{array}$ \\
\hline
\end{tabular}

4

Brady et al. (2015)

Synthesised evidence from reviews $(n=8)$

1, $2 \quad$ Lowe et al. (2012)

1,3

Goemeas et al. (2016)

Kennedy et al. (2015)
A study reporting the results of a thematic analysis of a national database of telephone enquiries made by registered nurses and midwives to a national regulatory body concerning their scope of practice

A survey among a randomised sample of 1997 ambulatory care nurse practitioners in the United States to examine their self-reported barriers to documentation of nursing practice utilising standardised nursing language in the electronic health record

\section{Contribution to the theme headings}

The study reported the different perspectives of primary care physicians and nurse practitioners on the role of nurse practitioners in PC and indicated divergence of agreement about their respective roles in the delivery of primary care

The study reported that three medication management, changing and evolving scope of practice and professional role boundaries were practitioners' main concerns that impacted on their scope of practice

The study reported on several barriers to utilising a standardised nursing language and these barriers constituted barriers impact of the nurse practitioners' care, rendering it unidentifiable for outcomes reporting purposes

2
Carney (2015)
$4,6 \quad \begin{aligned} & \text { Sangster-Gormley } \\ & \text { et al. (2011) }\end{aligned}$

Browne and Tarlier (2008)

\section{A discussion paper based on a review of} literature. Discusses the importance of providing meaningful advanced practice nursing role definition and clarity to improve international standards of nursing titles and scopes of practice

A review of literature and concept analysis advanced midwifery practice (AMPs)

A review paper that discusses and compares nursing and midwifery regulatory and professional bodies' scope of practice and associated decision-making frameworks
A review article aimed at exploring the regulation of advanced nurse practice internationally and to identify differences and commonalities across countries
Article presents themes around role clarity, professional identity, ability to enhance healthcare provision and interprofessional issues

The findings of the concept analysis supported a wide variety in the emergence, titles, roles and scope of practice of AMPs

The review identified two approaches to scope of practice regulation and associated decision-making frameworks: a policy and regulation driven and behaviour-oriented approach and an approach that promotes autonomous decision-making, professionalism and accountability

The review identified a lack of consistency in legislative systems internationally. Recognition of advanced practice varies with some nursing organisations have regulation in some countries and having voluntary certification

An integrative review guided by the Whittemore and Knafl method to examine the experience with and the factors influencing nurse practitioner role implementation in Canadian

A critical discourse analysis using the lens of social justice, based on research-based and grey literature
The review authors reported on the three concepts that emerged as factors influencing implementation: influence nurse practitioner role implementation in Canada: involvement, acceptance and intention

The authors argue that a critical social justice perspective is essential to sustaining longterm, socially responsive nurse practitioner roles and achieving greater equity in health and health care 
TABLE 2 (Continued)

$\begin{array}{cll}\text { Theme }^{\text {a }} & \text { Authors } & \text { Paper type and method } \\ 5 & \text { Elliot et al. (2016) } & \begin{array}{l}\text { A scoping review identifies the barriers and } \\ \text { enablers to advanced practitioner's ability to } \\ \text { enact their leadership role }\end{array} \\ \end{array}$

4,6

$$
\begin{aligned}
& \text { Delamaire and } \\
& \text { Lafortune (2010) }
\end{aligned}
$$

A review paper on the development of advanced practice nurses in twelve OECD countries, with a focus on descriptions of ANP roles in primary care and on evaluations of impacts on patient care and cost

\section{Contribution to the theme headings}

The review authors identified thirteen barriers to and eleven enablers of advanced practitioner's ability to enact their leadership role. The factors reported were in two broad categories, organisational-level factors, included mentoring, managerial and structural supports and case load, and practitioner-level factors related to personal attributes, knowledge, skills and values of the advanced practitioner

The review paper reported on the stage of development of advanced practice in the twelve countries and synthesised the published and grey literature evidence from evaluations of the impact and cost of advanced practice roles
Discursive papers and policy documents $(n=8)$

1 Stasa et al. (2014)

1 Bryant-Lukosius et al. (2004)

1 Foster and Flanders (2014)

2 Nardi (2014)

\section{$2,4,6$} Fougère et al. (2016)

2 Brassard and Smolenski (2011)
A discursive paper examining the international variability in how advanced practice nursing, and associated terms are defined and regulated across a variety of different English speaking countries

A discussion paper which examines six issues influencing the introduction of advanced practice nursing (APN) roles

A discussion paper on the difficulties encountered in the education and implementation of the clinical nurse specialist (CNS) role, including the barriers to optimisation of the role

A discursive paper that presents reflections on the major practice issues raised at the 7th International Nurse Practitioner/Advanced Practice Nursing Network Conference, in 2012

A discursive review paper aimed at precisely defining the term "advanced practice nurse (APN)," describing the state of development of APN roles and reviewing the factors motivating and hinder the implementation of APN in different countries

A policy report that discusses credentialing and privileging for advanced practice registered nurses (APRNs) in the United States, including the barriers to credentialing of hospital privileges, and outlines the benefits to consumers and the healthcare system when APRNs have hospital privileges
$2,3,6$
Archibald and Fraser (2013)

A discussion paper on nurse practitioners (NPs) in Canada focusing on the supports and regulation necessary for their optimal use in the healthcare system
Highlights a lack of clarity regarding the precise definitions of key terms surrounding the discussion of advanced practice

Discusses challenges associated with the introduction of APN roles

The discussion examines the issue of role clarity and the fact that CNSs lack of clearcut role definition

The paper identified that the major issues addressed at the conference included independent practice, barriers to practice, educational standards, and the APN role in research and evidence-based practice

Factors acting as barriers to practice expansion for nurses include physician resistance to APN roles, which is related to several factors, including potential overlap in nurses' and physicians' scope of practice and concerns over legal liability in cases of nursing malpractice and loss of income

The paper identified barriers associated with medical regulation and state laws and hospital by-laws to APRNs practising to full scope and when these barriers to credentialing and privileging are removed, APRNs can improve access and care, help to coordinate care, provide the transition planning and postdischarge care

The paper identified that barriers to mobilising NPs in Canada impede their integration into the Canadian healthcare system. There is a lack of uniformity between models of healthcare delivery across the different jurisdictions in and various levels of restriction on aspects of NPs' practice 
TABLE 2 (Continued)

\begin{tabular}{|c|c|c|c|}
\hline Theme $^{a}$ & Authors & Paper type and method & Contribution to the theme headings \\
\hline 6 & Malina and Izlar (2014) & $\begin{array}{l}\text { A discursive paper on Certified Registered } \\
\text { Nurse Anesthetists (CRNAs), with a focus on } \\
\text { the resistance from outside entities regarding } \\
\text { rights to practice to the full scope of their } \\
\text { education and experience. advanced practice } \\
\text { registered nursing (APRN) specialties }\end{array}$ & $\begin{array}{l}\text { The paper identifies and discusses the } \\
\text { sources of opposition to nurse anaesthetists } \\
\text { practicing to the full scope of their } \\
\text { education and training in the clinical arena } \\
\text { and in the educational milieu }\end{array}$ \\
\hline
\end{tabular}

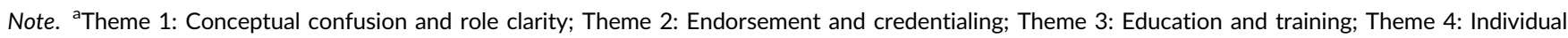
practitioners and their scope of practice; Theme 5: The work organisation and employers; Theme 6: Cost.

the emergence, titles, roles and scope of practice of advanced midwifery practice (AMP), and the lack of a clear conceptualisation and distinctiveness of AMP is a barrier to the realisation of the AMP role (Goemeas, Beeckman, Goossen, Shawe, \& Van Hecke, 2016).

The lack of agreement on the words and phrases associated with extended and expanded roles gives rise to uncertainty in the minds of individual practitioners, who may desire to take on a specialist or advanced practice role or may already occupy such a role. Where advanced practice nurses are unclear as to their precise responsibilities, health professionals may also be unclear as to the extent of the advanced practitioner's expertise, and patients may not know when to consult an advanced practice nurse (Stasa et al., 2014).

The literature indicates a recurring theme concerning both specialist and advanced practice roles, that of the blurring of role boundaries between, what are generally perceived to be, traditional domain activities and functions of nursing and medicine. Several authors refer to this aspect of advanced practice and how lack of role clarity can impact on scope of practice within advanced nursing roles (Campbell \& Profetto-McGrath, 2013; Fealy et al., 2015; Foster \& Flanders, 2014; Franks \& Howarth, 2012; Gerrish et al., 2012; Heale \& RieckBuckley, 2015; Lowe et al., 2012; Poghosyan et al., 2013). For example, Heale and Rieck-Buckley (2015) identified a general lack of understanding of the advanced practice nursing role and disparities in advanced practice nursing roles between healthcare settings. Likewise, Lowe et al. (2012) refer to lack of role clarity around aspects like nomenclature, role definition and role boundaries, and argue that role clarity can bring a sense of professional identity and the ability to provide consistent outcome measures for the various advanced practice roles. NPs in the United States can also experience role conflict in circumstances in which they are both NP and entrepreneur, such as owning and managing a clinic (Sharpe, 2014).

Advanced practitioners' knowledge and skills enable the effective expression of the role (Elliot, Begley, Sheaf, \& Higgins, 2016). Like advanced practitioners, clinical specialists can adapt to a variety of professional roles, including providing direct care and educating staff through having a broad repertoire of knowledge and skills; however, this flexibility can act as a barrier, leading to a blurring rather than clarity regarding role parameters (Foster \& Flanders, 2014). Such role ambiguity can be overcome by nurse and midwife practitioners themselves clearly articulating their specialist or advanced role functions, either verbally in context, or through detailed job descriptions (Foster \& Flanders, 2014).

\subsection{Endorsement and credentialing}

The development of specialist and advanced practice roles is contingent on official endorsement from each country's national regulatory authority, through the process of professional regulation and accreditation, and endorsement must also be supported by service providers and employers. Endorsement of specialist and advanced practice roles generally involves establishing agreed practice standards by a regulatory authority, the provision of accredited education and training programmes, and the accreditation and/or registration of the individual practitioner and/or the place of practice.

As physicians generally have clinical jurisdiction over the admission and discharge of patients, advanced practice roles also generally require endorsement from the medical profession (Heale \& RieckBuckley, 2015) and the implicit support of other healthcare professionals. The medical profession in the United States has endorsed advanced practice nursing, as evidenced in the Institute of Medicine's (IOM) support for the principle that nurses should practice to the full extent of their professional education and training, and that scope-of-practice barriers should be removed (IOM, 2010). Likewise, in Ireland, the medical profession implicitly endorses advanced practice roles by actively participating in the regulatory process of site and practitioner accreditation. Despite this, there is evidence globally that the medical profession continues to seek to control nursing practice through retention of physician-led healthcare teams and through clinical authority (Nardi, 2014). The lack of professional autonomy over its own practice is compounded by a lack of strategic leadership in government and nursing organisations in support of specialist and advanced practice roles (Heale \& Rieck-Buckley, 2015).

A professional regulator's official endorsement is generally provided through published standards for educational preparation and practice and through scope-of-practice frameworks, and these, in turn, can determine how practice expansion develops (Fealy et al., 2015). In a comparative analysis of twelve regulatory authorities' scope-of-practice frameworks, Kennedy et al. (2015) identified a dual-approach typology: a policy-driven and behaviour-oriented approach and an approach that enables autonomous decisionmaking, professionalism and accountability. Although not mutually exclusive, the former type stresses legislation and rules and is more likely to give rise to practice restrictions, that is, to circumscribe what nurses can and cannot do, and therefore act as a barrier to practice expansion (Fougère et al., 2016). To converse, the latter 
type seeks to promote individual responsibility and accountability for decision-making and is therefore more likely to support practice expansion (Kennedy et al., 2015). Based on a systematic review of literature on the regulation of advanced nurse practitioners (ANPs), Carney (2015) reported that, although several countries have statutory mechanisms for regulating advanced practice, many do not, with evidence of stalled or nonexistent legislation. In addition, the variance in titles and levels of education across countries when determining what counts as advanced practice also contributes to the lack of official recognition of the role and adversely impacts on role performance (Carney, 2015).

The literature points to the importance of credentialing through various mechanisms, including registration legislation and professional regulation, licensure and certification, training programme accreditation, practice experience and titling (Nardi, 2014). As a key enabler of specialist and advanced practice roles, credentialing facilitates a better understanding of expanded roles and, conversely, its absence impedes practitioners' ability to practice to the full scope of their practice (Heale \& Rieck-Buckley, 2015). An explicit policy or framework to guide the development and accreditation of specialist and advanced practice roles also facilitates the fuller expression of the leadership dimension of such roles (Higgins et al., 2014). Credentialing also provides the systems for defining role parameters, thereby promoting safe and competent practice (Carney, 2015).

Worldwide, barriers to advanced practice nursing are associated with the extent of credentialing. Based on an online survey of national nursing associations and nursing health policymakers, Heale and Rieck-Buckley (2015) examined the status of regulation for advanced practice nursing and reported wide variation in regulation and credentialing criteria across countries. With data from 30 countries, the authors identified explicit credentialing criteria in 19 countries, such as licensure or mandatory educational programmes, for a variety of roles, including NP, ANP and specialist nurse. Among the reported barriers to advanced practice nurses practising to full scope of practice were legislative limitations and a lack of regulation of the role, lack of title protection and low nursing representation in policy development (Heale \& Rieck-Buckley, 2015).

Regulatory barriers restricting scope of practice exist in relation to the development of NP roles, particularly in individual states of the United States (Brassard \& Smolenski, 2011; Lowe et al., 2012; Poghosyan et al., 2013) and Canada (Archibald \& Fraser, 2013). Although a practitioner may have the credentials to perform certain diagnostic and treatment procedures, the individual practitioner must be privileged or granted permission by their employing hospital, to perform such procedures in certain jurisdictions. In the United States, credentialing and privileging historically applied to physicians only (Brassard \& Smolenski, 2011). The process is normally governed by local hospital by-laws, but with the advent of advanced practice registered nurses (APRNs) in the United States, this process also applies to nurses. However, by-laws can vary from one hospital to another, and hence, APRNs may not obtain clinical privileges to practice across all hospitals (Brassard \& Smolenski, 2011). In addition, scope-of-practice restrictions also exist in US state and federal legislation, including Medicare legislation, and in state laws that prevent APRNs from conducting a patient history and physical examination. Differences across Canadian states also place restrictions on the extent to which NPs can operate in that country, where there is a lack of uniformity between models of healthcare delivery across the different jurisdictions and different levels of restriction on aspects of practice, like prescriptive authority (Archibald \& Fraser, 2013).

\subsection{Education and training}

The growth and sustainability of advanced practice roles depend on practitioners' ability to provide primary-, secondary- and tertiarylevel care, including preventive and health promotion strategies, to individuals and families (Browne \& Tarlier, 2008). Specialist and advanced practice roles therefore require a repertoire of advanced clinical skills, including assessment and prescribing skills in acute care, secondary prevention in the care of older people and tertiary prevention in care of persons with a chronic illness (Fagerström, 2009). Hence, the development of specialist and advanced practice roles can be enabled or impeded by the extent of educational provision and practitioner access to continuing education and role-specific training. Support for and access to continuing professional education are factors that enable nurses and midwives to engage in specialist and advanced practice activities (Fealy et al., 2015; Goemeas et al., 2016), and where nurses and midwives have assumed expanded practice roles, such as independent prescribing, they have reported that their educational preparation provided them with the requisite skills and training for the expanded role (Drennan et al., 2009). To converse, where nurses encountered access, time and/or cost barriers to appropriate preparatory or continuing education, they were potentially hampered in fully developing their role as NPs (Baxter et al., 2013; McKenna, Halcomb, Lane, Zwar, \& Russell, 2015).

Public awareness of the fact that nurses can operate at different levels of expertise in providing a tailored service to specific patient groups is a key enabler to the development of specialist and advanced practice roles, as public awareness will give rise to public support (Archibald \& Fraser, 2013). Several authors cite public support as an important factor in the development of such roles (Franks \& Howarth, 2012). Accreditation frameworks for professional training and the availability of special preparatory training are necessary to grow a cadre of advanced practice nurses and midwives; hence, access to special professional training is an enabler of expanded scope-of-practice roles (Fealy et al., 2015) and, conversely, inaccessibility of training programmes and a lack of accreditation of training programmes represent barriers to role development and advancement (Goemeas et al., 2016; Heale \& Rieck-Buckley, 2015).

\subsection{Individual practitioners and their scope of practice}

Evidence of both nurses' and midwives' experiences in role expansion indicates that many embrace role expansion and perform 
effectively in expanded scope-of-practice roles (Fealy et al., 2015); however, nurses and midwives may experience scope of practice as either enabling or restricting (Casey et al., 2015). Several individuallevel factors have been identified as barriers to role expansion; among these intrinsic barriers include self-perceived lack of role clarity, concerns over role boundaries and self-perceived level of clinical autonomy in assuming expanded scope-of-practice roles (Brady et al., 2015; Fealy et al., 2015). Practitioners' concerns when expanding practice also include uncertainty regarding clinical autonomy (Begley et al., 2010) and fear of adverse legal consequences when expanded role activities were not sanctioned by legislation or scope of practice guidelines (Brady et al., 2015; Drennan et al., 2009; Fealy et al., 2015).

Expanding practice can improve nurses' job satisfaction (Hoodless \& Bourke, 2009) and career opportunities (Fougère et al., 2016). Evidence from studies conducted in Ireland indicates that nurses and midwives welcome opportunities to expand their practice where opportunities and relevant preparation for expanded scope-of-practice roles are available (Drennan et al., 2009; Fealy et al., 2015) or where they see patient benefits arising (Begley et al., 2010). For example, Drennan et al. (2009) demonstrated that nurses and midwives are willing to embrace prescriptive authority as an aspect of role expansion.

Although practitioners may occupy designated specialist or advanced practice roles, the extent to which they can fully express the role may be contingent on their self-perceived understanding of their scope of practice within the role. For example, Wilkes, Luck, and O'Baugh (2015) reported that fewer than half of a sample of CNC in Sydney, Australia, believed that research was part of their role and this was reflected in the fact that half of the sample did not actually conduct research. Sangster-Gormley, Martin-Misener, Downe-Wamboldt, and Dicenso (2011) identified barriers among NPs in Canada, which constrained them in their ability to practice to their full scope. Among the barriers, which they identified, were resistance from physicians, lack of funding for advanced practice roles, fee-for-service remuneration models, overlapping role functions between registered nurses and NPs, and restrictive legislation.

The disposition of the medical profession constitutes a significant enabler of or barrier to advanced practice nurses' ability to practise to full scope. Results from a national survey of 467 primary care NPs and 505 physicians in the United States indicated that NPs and physicians had polarised views on the extent to which role expansion should take place, whether NPs could practice independently as leaders of patient-centred medical homes, and whether advanced practice nurses provided the same quality of care as physicians (Donelan, DesRoches, Dittus, \& Buerhaus, 2013). Based on interview data from a purposive sampling of 23 NPs in primary care settings, Poghosyan et al. (2013) reported on the elements that either supported or restricted NPs' scope of practice; these included the regulatory environment, as reflected in the requirement to have physician supervision in nurse prescribing, and physician collaboration and support. Related barriers external to the individual practitioner include opposition from medical colleagues (Fealy et al., 2015; Heale \& Rieck-Buckley, 2015), from the medical profession more generally (Delamaire \& Lafortune, 2010; Fougère et al., 2016) and from medical organisations and pharmacists (Heale \& Rieck-Buckley, 2015). Physician resistance to APN roles relates to potential overlap in nurses' and physicians' scope of practice and loss of activities, ANPs' autonomy and independence, physician concerns over legal liability in cases of nursing malpractice, and ANPs' skills and expertise (Fougère et al., 2016).

Based on case studies of ANPs in UK hospital and primary care settings, Gerrish et al. (2012) identified factors that influence ANPs' ability to promote evidence-based practice (EBP) among front-line nurses; these included the individual ANP's own knowledge and skills in EBP, clinical credibility with front-line staff and leadership style. A lack of a standardised nursing language in the electronic medical record is also cited as a barrier (Conrad, Hasenau, \& Stocker-Schneider, 2012). Higgins et al. (2014) identified four "mediating factors" that enabled clinical nurse specialist and ANPs in Ireland to enact their clinical and professional leadership roles: a framework for professional role development; opportunities to act as leaders; mechanisms for sustaining leadership; and the personal attributes of individual practitioners. Opportunities to act as leaders were available in learning forums, platforms to showcase innovation and developments, opportunities to network and build strategic alliances, and the requirement to maintain a portfolio of professional and personal development (Higgins et al., 2014). The value that society places on certain fields of practice, such as child protection, can act as a factor in enabling specialists and advanced practitioners to practice to the full scope of their education and professional competence (Franks \& Howarth, 2012).

\section{5 | The work organisation and employers}

A frequently reported factor in either enabling or constraining specialist and advanced practice roles is the degree of support from others, especially work colleagues and managers of service (Elliot et al., 2016; Fealy et al., 2015; Franks \& Howarth, 2012; Gerrish et al., 2012; McKenna et al., 2015). Without the support from healthcare managers, advanced practitioners will not realise their leadership role as change agents and innovators and role expression will remain at the level of clinical practice (Elliot et al., 2016). Poghosyan et al. (2013) reported a lack of access to supports and resources to conduct practice and a lack of representation and involvement in administrative decision-making as barriers to NPs in the effective conduct of their practice. McKenna et al. (2015) reported organisational-level barriers to the development of advanced nursing roles in Australian practice settings, including a lack of management support, time constraints that curtailed nurses in their ability to participate in advanced care focussed activities, and having a distinct nursing workspace in which to practice within the general practice setting.

The development of specialist and advanced practice roles is contingent, in part, on the extent to which there is empirical evidence to demonstrate role effectiveness in patient and service 
outcomes, and much of this evidence comes from practitioner-generated outcomes data. Franks and Howarth (2012) identified a lack of evidence to support the value of the nurse consultant (NC) role in the United Kingdom as a threat to the role development and this threat inhered in the inability of NCs to engage in research to demonstrate their effectiveness. A key function of the role of specialist and advanced practice nurses and midwives is the ability to engage in and promote EBP. The factors that influence this aspect of the role also include the organisation's commitment to EBP and support from managers and medical colleagues (Gerrish et al., 2012). Campbell and Profetto-McGrath (2013) reported that the major challenges faced by Canadian clinical nurse specialists in promoting EBP were role strain, lack of support and resources, and role ambiguity.

\section{6 | Cost}

Specialist and advanced practice roles offer the potential to reduce health service costs, where otherwise the services are provided by physicians and surgeons, who traditionally command a higher salary than their nurse and midwife counterparts. NPs are viewed as a viable alternative to physicians when dealing with growing healthcare costs, as they can provide cost-effective, high-quality care (Archibald \& Fraser, 2013). Hence, where savings to the health system can be demonstrated, this can act as an enabler of role expansion into specialist and advanced practice positions. Findings from the Irish National Evaluation of Clinical Nurse and Midwifery Specialist and Advanced Nurse/Midwife Practitioner Roles (SCAPE) project indicated that the introduction of clinical and advanced practice roles in the Irish health system was, at the very least, cost neutral (Begley et al., 2010). However, a study conducted across twelve OECD countries indicated that the cost savings to be accrued from the proliferation of advanced nursing roles may be less than anticipated, as nurses occupying these roles conduct longer consultations than their medical counterparts and make more referrals, which result in more diagnostic tests (Delamaire \& Lafortune, 2010).

One aspect of cost that is cited as a barrier to advanced practice nursing in the United States is reimbursement for services. Several authors have reported that mechanisms for reimbursement present a barrier in relation to aspects like recognition, equity and status, and the extent to which they can deliver service (Sharpe, 2014), or practice within their scope of practice (Poghosyan et al., 2013). Other authors have similarly reported the problem of advanced practitioners in the United States encountering difficulties with reimbursement for services (Malina \& Izlar, 2014; Sangster-Gormley et al., 2011). For example, in a review article, Malina and Izlar (2014) reported the cost of practice doctorate training and restrictions on direct practitioner reimbursements for service under the Medicare programme as barriers to advanced practice registered nursing specialties and certified registered nurse anaesthetists in practicing to the full scope of their education and training. Fee-for-service payments for doctors and the risk of loss of income can also act as a barrier to the development of advanced practice roles in primary care (Fougère et al., 2016).

\section{CONCLUSION}

Scope-of-practice issues related to role expansion, role boundaries, clinical jurisdiction and professional regulation continue to exercise national health systems and service organisations, professional regulators, nurses and midwives and the medical profession. These issues get played out in individual countries in the national debates and legislative changes that seek to position nurses as key autonomous professionals offering advanced, but complementary, skills and services in the face of population healthcare needs and demands.

Many developed countries are at very different stages in implementing advanced practice roles (Carney, 2015; Fougère et al., 2016). As they move towards more independent practice, ANPs face both enablers and barriers, both from within and outside the profession, including a failure of regulatory and accrediting bodies to support independent practice, including prescribing privileges, and a lack of endorsement from the medical profession. Legal and scope-of-practice regulatory frameworks that circumscribe what nurses and midwives can and cannot do will remain a major barrier to role development and implementation. Regulatory barriers also relate to the need to balance practice restriction with practice expansion (Fealy et al., 2015).

The literature demonstrates that several factors enable nurses and midwives to expand their practice into specialist and advanced practice roles; these include factors intrinsic to the practitioner, including a professional disposition to practice to optimum scope and a desire for career advancement. Factors external to the practitioner, which enable role expansion, are frequently local to the practitioner's workplace, including support from peers, other healthcare professionals and the work organisation. The wider professional and healthcare contexts, which include the service-driven need for nurses and midwives with specialist and advanced clinical skills, is also a major driver of role expansion into specialist and advanced practice roles.

Advance practice nurses and midwives are constrained in their ability to practice to the full extent of their education and training and these constraints exist as regulatory, institutional and cultural barriers (Fealy et al., 2015; Kleinpell et al., 2014). Empirical studies have examined scope of practice from the perspective of practitioners, usually through self-reports of their practices and/or by eliciting their opinions and perspectives. Studies that have specifically examined enablers and barriers to advanced practice have been, in the main, based on small local studies, often involving purposive samples of practitioners working in certain practice contexts, such as primary care. This fact represents a significant limitation in the evidence base concerning enablers and barriers to specialist and advanced practice. Therefore, review and discursive articles that examine national and regional policies and developments and trends in the field provide important evidence that goes some way to compensating for this lacuna in the empirical evidence.

\section{1 | Limitations}

This discursive paper was based on the method of rapid review. Although rapid reviews can be useful in synthesising evidence in 
time-sensitive situations (O'Leary et al., 2017), there are limitations to the method. These include the risk that streamlining the search and screening steps may result in some pertinent evidence being missed, thereby introducing the potential for bias in reporting the evidence (O'Leary et al., 2017), and the risk of uncertainty due to possible over-reliance on studies that do not meet strict criteria of quality (Tricco et al., 2015). In addition, there are risks that data abstraction can be less rigorous and that review team members may not have sufficient prior training or experience in systematic reviewing to prepare them to use the rapid review method (O'Leary et al., 2017).

\section{6 | RELEVANCE TO CLINICAL PRACTICE}

This discursive paper addressed an enduring and significant challenge for nursing and midwifery across clinical practice, education and professional regulation, as well as wider health and organisational policy and practice. The fact that nursing in developed western countries continues to experience challenges in describing, defining, regulating and successfully enacting expanded scope-of-practice roles suggests that disciplinary development in nursing remains iterative and developmental, and is somewhat restricted in its development from both internal and external forces. Enabling nurses and midwives to practice to the full scope of their education and expertise, and thereby maximise their disciplinary contribution to health care, is a global challenge for the disciplines' leaders, a national challenge for professional regulators and a local challenge for healthcare organisations and services that employ nurses and midwives. It is also a challenge for individual practitioners, who are seeking opportunities for role expansion and the fullest expression of the scope of their practice. A global response can come from influential bodies like the World Health Organisation and the International Council of Nurses. National responses can come from nursing and midwifery regulators, working in consort with key stakeholders, including governmental nursing and midwifery policy and health planning units, the academic sector, the medical and other healthcare professionals, employers and practitioners themselves. There is evidence that these multistakeholder collaborations are now taking place in countries like Ireland, where a revised model of advanced practice education and credentialing has been introduced through a multisector partnership approach (Department of Health, 2017).

\section{ACKNOWLEDGEMENTS}

The authors are grateful to Professor Andrew Cashin and Professor Kate Gerrish, who acted as project advisors.

\section{CONFLICT OF INTEREST}

None.

\section{CONTRIBUTIONS}

Study design: MC, LO'C, DO'L, GF, MMcN, RS, DO'B; data collection: GF, DO'L, DS; and manuscript preparation: GF, DO'L.

\section{ORCID}

Gerard M Fealy (iD http://orcid.org/0000-0002-0505-9808

Laserina O'Connor (iD http://orcid.org/0000-0003-3020-9246

Rita Smith iD http://orcid.org/0000-0002-9090-9642

\section{REFERENCES}

Archibald, M. M., \& Fraser, K. (2013). The potential for nurse practitioners in health care reform. Journal of Professional Nursing, 29, 270275. https://doi.org/10.1016/j.profnurs.2012.10.002

Baxter, P., DiCenso, A., Donald, F., Martin-Misener, R., Opsteen, J., \& Chambers, T. (2013). Continuing education for primary health care nurse practitioners in Ontario, Canada. Nurse Education Today, 33(4), 353-357. https://doi.org/10.1016/j.nedt.2012.07.018

Begley, C., Murphy, K., Higgins, A., Elliott, N., Lalor, J., Sheerin, F., ... MacNeela, P. (2010). Evaluation of clinical nurse and midwife specialist and advanced nurse and midwife practitioner roles in Ireland (SCAPE) Final Report. Dublin, Ireland: National Council for the Professional Development of Nursing and Midwifery.

Bradway, C., Trotta, R., Bixby, M. B., McPartland, E., Wollman, C. M., Kapustka, H., ... Naylor, M. D. (2012). A qualitative analysis of an advanced practice nurse-directed transitional care model intervention. The Gerontologist, 52 (3), 394 407. https://doi.org/10.1093/geront/gnr078

Brady, A. M., Fealy, G., Rohde, D., Casey, M., Hegarty, J., Kennedy, C., ... Prizeman, G. (2015). 'Am I covered?': An analysis of a national enquiry database on scope of practice. Journal of Advanced Nursing, 71(10), 2402-2412. https://doi.org/10.1111/jan.12711

Brassard, A., \& Smolenski, M. (2011). Removing barriers to advanced practice registered nurse care: Hospital privileges. Washington, DC: AARP Public Policy Institute.

Browne, A. J., \& Tarlier, D. S. (2008). Examining the potential of nurse practitioners from a critical social justice perspective. Nursing Inquiry, 15(2), 83-93. https://doi.org/10.1111/j.1440-1800.2008.00411.x

Bryant-Lukosius, D., DiCenso, A., Browne, G., \& Pinelli, J. (2004). Advanced practice nursing roles: Development, implementation and evaluation. Journal of Advanced Nursing, 48(5), 519-529. https://doi. org/10.1111/j.1365-2648.2004.03234.x

Campbell, T. D., \& Profetto-McGrath, J. (2013). Skills and attributes required by clinical nurse specialists to promote evidence-based practice. Clinical Nurse Specialist, 27(5), 245-254. https://doi.org/10. 1097/NUR.0b013e3182a0ba68

Carney, M. (2015). Regulation of advanced nurse practice: Its existence and regulatory dimensions from an international perspective. Journal of Nursing Management, 24(1), 105-114. https://doi.org/10.1111/ jonm.12278

Casey, M., Fealy, G., Kennedy, C., Hegarty, J. M., Prizeman, G., McNamara, M., ... Rhode, D. (2015). Nurses', midwives' and key stakeholders' experiences and perceptions of a scope of nursing and midwifery practice framework. Journal of Advanced Nursing, 71(6), 1227-1237. https://doi.org/10.1111/jan.12603

Cashin, A., Buckley, T., Donoghue, J., Heartfield, M., Bryce, J., Cox, D., ... Dunn, S. C. (2015). Development of the nurse practitioner standards for practice Australia. Policy, Politics, \& Nursing Practice, 16(1-2), 2737. https://doi.org/10.1177/1527154415584233

Conrad, D., Hasenau, S. M., \& Stocker-Schneider, J. (2012). Identifying the barriers to use of standardized nursing language in the electronic health record by the ambulatory care nurse practitioner. Journal of the American Academy of Nurse Practitioners, 24, 443-451. https:// doi.org/10.1111/j.1745-7599.2012.00705.x

Darker, C. D. (2013). Integrated healthcare in Ireland: A critical analysis and a way forward. Dublin, Ireland: Adelaide Health Foundation/Trinity College Dublin. 
Delamaire, M., \& Lafortune, G. (2010). Nurses in advanced roles: A description and evaluation of experiences in 12 developed Countries. OECD Health Working Papers, No. 54. Paris, Frrance: OECD Publishing. https://doi.org/10.1787/5kmbrcfms5g7-en

Department of Health. (2017). Developing a policy for graduate, specialist and advanced nursing \& midwifery practice: Consultation paper. Dublin, Ireland: Department of Health.

Donelan, K., DesRoches, C. M., Dittus, R. S., \& Buerhaus, P. (2013). Perspectives of physicians and nurse practitioners on primary care practice. New England Journal of Medicine, 368(20), 1898-1906. https://doi.org/10.1056/NEJMsa1212938

Drennan, J., Naughton, C., Allen, D., Hyde, A., Felle, P., O'Boyle, K., ... Butler, M. (2009). Independent evaluation of the nurse and midwife prescribing initiative. Dublin, Ireland: University College Dublin.

Elliot, N., Begley, C., Sheaf, G., \& Higgins, A. (2016). Barriers and enablers to advanced practitioners' ability to enact their leadership role: A scoping review. International Journal of Nursing Studies, 60, 24-45. https://doi.org/10.1016/j.ijnurstu.2016.03.001

Fagerström, L. (2009). Developing the scope of practice and education for advanced practice nurses in Finland. International Nursing Review, 56, 269-272. https://doi.org/10.1111/j.1466-7657.2008.00673.x

Fealy, G., Rohde, D., Casey, M., Brady, A. M., Hegarty, J., Kennedy, C., ... Prizeman, G. (2015). Facilitators and barriers in expanding scope of practice: Findings from a national survey of Irish nurses and midwives. Journal of Clinical Nursing, 24(23-24), 3615-3626. https://doi. org/10.1111/jocn.12980

Foster, J., \& Flanders, S. (2014). Challenges in clinical nurse specialist education and practice. Online Journal of Issues in Nursing, 19(2), 10913734. https://doi.org/10.3912/OJIN.Vol19No02Man01

Fougère, B., Morley, J. E., Decavel, F., Nourhashémi, F., Abele, P., Resnick, B., ... Vellas, B. (2016). Development and implementation of the advanced practice nurse worldwide with an interest in geriatric care. Journal of the American Medical Directors Association, 17(9), 782-788. https://doi.org/10.1016/j.jamda.2016.05.009

Franks, H., \& Howarth, M. (2012). Being an effective nurse consultant in the English National Health Service: What does it take? A study of consultants specializing in safeguarding. Journal of Nursing Management, 20 (7), 847-857. https://doi.org/10.1111/j.1365-2834.2012.01353.x

Gardner, G., Chang, A., \& Duffield, C. (2007). Making nursing work: Breaking through the role of confusion of advanced practice nursing. Journal of Advanced Nursing, 57(4), 382-391. https://doi.org/10. 1111/j.1365-2648.2007.04114.x

Gerrish, K., Nolan, M., McDonnell, A., Tod, A., Kirshbaum, M., \& Guillaume, L. (2012). Factors influencing advanced practice nurses' ability to promote evidence-based practice among frontline nurses. Worldviews Evidence Based Nursing, 9(1), 30-39. https://doi.org/10.1111/j. 1741-6787.2011.00230.x

Giles, M., Parker, V., \& Mitchell, R. (2014). Recognising the differences in the nurse consultant role across context: A study protocol. BMC Nursing, 13, 30. https://doi.org/10.1186/1472-6955-13-30

Goemeas, R., Beeckman, D., Goossen, J., Shawe, J., \& Van Hecke, A. (2016). Advanced midwifery practice an evolutionary concept analysis. Midwifery, 42, 29-37. https://doi.org/10.1016/j.midw.2016.09.004

Ham, C., Dixon, G., \& Brooke, G. (2012). Transforming the delivery of health and social care: The case for fundamental change. London, UK: The King's Fund.

Heale, R. R., \& Rieck-Buckley, C. (2015). An international perspective of advanced practice nursing regulation. International Nursing Review, 62(3), 421-429. https://doi.org/10.1111/inr.12193

Higgins, A., Begley, C., Lalor, J., Coyne, I., Murphy, K., \& Elliott, N. (2014). Factors influencing advanced practitioners' ability to enact leadership: A case study within Irish healthcare. Journal of Nursing Management, 22, 894-905. https://doi.org/10.1111/jonm.12057

Higgins, J., \& Green, S. (2006). Cochrane Handbook for Systematic Reviews of Interventions. Chichester: Wiley-Blackwell.
Hoodless, M., \& Bourke, L. (2009). Expanding the scope of practice for enrolled nurses working in an Australian rural health service: Implications for job satisfaction. Nurse Education Today, 29(4), 432-438. https://doi.org/10.1016/j.nedt.2008.09.002

Institute of Medicine. (2010). The future of nursing: Leading change, advancing health. Washington, DC: National Academies Press.

Kennedy, C., O'Reilly, P., Fealy, G. M., Casey, M., Brady, A. M., McNamara, M., ... Hegarty, J. (2015). Comparative analysis of nursing and midwifery regulatory and professional bodies' scope of practice and associated decision-making frameworks: A discussion paper. Journal of Advanced Nursing, 71(8), 1797-1811. https://doi.org/10.1111/jan.12660

Kleinpell, R., Scanlon, A., Hibbert, D., DeKeyser Ganz, F., East, L., Fraser, D., ... Beauchesne, M. (2014). Addressing issues impacting advanced nursing practice worldwide. Online Journal of Issues in Nursing, 19(2), 5. https://doi.org/10.3912/OJIN.Vol19No02Man05

Lowe, G., Plummer, V., O'Brien, A. P., \& Boyd, L. (2012). Time to clarify: The value of advanced practice nursing roles in health care. Journal of Advanced Nursing, 68(3), 677-685. https://doi.org/10.1111/j.13652648.2011.05790.x

Malina, D., \& Izlar, J. (2014). Education and practice barriers for certified registered nurse anesthetists. Online Journal of Issues in Nursing, 19(2), 3. https://doi.org/10.3912/OJIN.Vol19No02Man03

McKenna, L., Halcomb, E., Lane, R., Zwar, N., \& Russell, G. (2015). An investigation of barriers and enablers to advanced nursing roles in Australian general practice. Collegian, 22, 183-189. https://doi.org/ 10.1016/j.colegn.2015.02.003

Nardi, D. A. (2014). Global trends and issues in APN practice: Engage in the change. Professional Nursing, 30(3), 228-232. https://doi.org/10. 1016/j.profnurs.2013.09.010

O'Leary, D., Casey, M., Stokes, D., Fealy, G., O'Brien, D., Smith, R., ... Egan, C. (2017). Using rapid reviews in nursing and midwifery research: An example from a study commissioned to inform policy-making. Journal of Advanced Nursing, 73(3), 742-752. https://doi.org/10.1111/jan.13231

Poghosyan, L., Nannini, A., Smaldone, A., Clarke, S., O'Rourke, N. C., Rosato, B. G., \& Berkowitz, B. (2013). Revisiting scope of practice facilitators and barriers for primary care nurse practitioners: A qualitative investigation. Policy, Politics, \& Nursing Practice, 14(1), 6-15. https://doi.org/10.1177/1527154413480889

Sangster-Gormley, E., Martin-Misener, R., Downe-Wamboldt, B., \& Dicenso, A. (2011). Factors affecting nurse practitioner role implementation in Canadian practice settings: An integrative review. Journal of Advanced Nursing, 67(6), 1178-1190. https://doi.org/10.1111/j. 1365-2648.2010.05571.x

Sharpe, D. B. (2014). Decreasing barriers for nurse practitioner social entrepreneurship. Journal of the American Association of Nurse Practitioners, 26, 562-566. https://doi.org/10.1002/2327-6924.12126

Stasa, H., Cashin, A., Buckley, T., \& Donoghue, J. (2014). Advancing advanced practice: Clarifying the conceptual confusion. Nurse Education Today, 34(2), 356-361. https://doi.org/10.1016/j.nedt.2013.07.012

Tricco, A. C., Antony, J., Zarin, W., Strifler, L., Ghassemi, M., Ivory, J., ... Straus, S. E. (2015). A scoping review of rapid review methods. BMC Medicine, 13(1), 1-15.

Wilkes, L., Luck, L., \& O'Baugh, J. (2015). The role of a clinical nurse consultant in an Australian Health District: A quantitative survey. BMC Nursing, 14, 25. https://doi.org/10.1186/s12912-015-0075-9

How to cite this article: Fealy GM, Casey M, O'Leary DF, et al. Developing and sustaining specialist and advanced practice roles in nursing and midwifery: A discourse on enablers and barriers. J Clin Nurs. 2018;27:3797-3809. https://doi.org/10.1111/jocn.14550 